\title{
Desenvolvimento territorial com base nas suas potencialidades: aplicação da matriz de condicionantes, potencialidades e deficiências - CPD
}

\section{Andressa Morgan}

Mestranda em Administração pela Universidade do Oeste de Santa Catarina (UNOESC). Endereço para contato: Fazenda Zandavalli - Interior - Guatambu - SC

CEP: 89817-000 - E-mail: dressamorgan@hotmail.com

\section{Josiane Weber}

Administradora da Universidade Federal da Fronteira Sul (UFFS). Endereço para contato: Avenida Fernando Machado, 108 - Centro - Chapecó - SC

CEP: 89802-112 - E-mail: josiweber@yahoo.com.br

\section{Cristiane Teresinha Agnolin}

Mestranda no Programa de Mestrado Profissional em Administração da Universidade do Oeste de Santa Catarina (UNOESC).

Endereço para contato: Rua Delfino Paludo, 358 - Bairro Nazaré - Concórdia - SC

CEP: 89700-000 - E-mail: cristiane.talento@hotmail.com

\section{Rójis Juarez Bernardy}

Professor da Universidade do Oeste de Santa Catarina (UNOESC).

Endereço para contato: Quintino Bocaiuva, 148D - Centro - Chapecó - SC

CEP: 89801-080 - E-mail: rogis.bernardy@unoesc.edu.br

Recebido em 24 de maio de 2015. Aceito em 12 de agosto de 2015.

\section{RESUMO}

Este artigo apresenta uma proposta de desenvolvimento para gestão de pequenas propriedades rurais do município de Guatambu (SC). Foi elaborado um diagnóstico com os dados referentes às propriedades rurais do município, identificando as suas fragilidades e potencialidades e aplicada a matriz de Condicionantes, Potencialidades e Deficiências (CPD). Por fim, sugeriu-se um modelo de gestão para as pequenas propriedades rurais. O estudo se deu por meio de pesquisa descritiva, com enfoque qualitativo. Com relação aos procedimentos metodológicos trata-se de um estudo de caso. Constataram-se algumas das dificuldades encontradas nas pequenas propriedades rurais como: as más condições das estradas, os problemas habitacionais, a ausência de meios de comunicação como internet e telefone, fato que dificulta o acesso à informação e a permanência dos jovens no campo. Percebeu-se a necessidade de diversificar a produção, visando garantir a renda do pequeno agricultor. Identificaram-se, também, divergências entre o que as entidades consideram questões de maior relevância e a realidade do pequeno produtor. Conclui-se que se faz necessário oferecer alternativas para diversificação da produção, promover maior diálogo entre os agricultores e as entidades a fim de proporcionar melhores condições de vida para as famílias do campo, garantindo a sua permanência e diminuindo o êxodo rural.

\section{Palavras chave}

Desenvolvimento Municipal; Agricultura familiar; Matriz CDP. 


\section{ABSTRACT}

This article proposes a model of development for management of small rural farms in Guatambu (SC). A diagnosis with the data on rural farms surveyed was prepared, identifying their weaknesses and potential applied to matrix Constraints, Potentials and Disabilities (CPD). Finally, it was suggested a management model for small farms. The study was made through descriptive research with qualitative approach. Regarding the methodological procedures it is a case study. It appears that some of the difficulties found in small farms as the poor condition of roads, housing problems, the lack of media such as internet and telephone, a fact that complicates access to information and the permanence of young people in the field. It was felt the need to diversify production, and aimed at the small farmer income. It also identified differences between the entities consider most relevant issues and the reality of the small producer. We conclude that it is necessary to offer alternatives to diversify the production, promote greater dialogue between farmers and authorities to provide better living conditions for families of the field ensuring its permanence and reducing the rural exodus.

\section{Keywords}

Municipal Development; Family farming; Matrix CDP

\section{Introdução}

O desenvolvimento regional é decorrente do crescimento sustentável de vários fatores intrínsecos de uma dada região. No que tange a região Oeste de Santa Catarina, um dos aspectos que tem extrema relevância é a agricultura, mais especificamente, a atividade realizada em pequenas propriedades rurais. Uma análise destas propriedades permite verificar que parte delas são administradas pelas próprias famílias, configurando um cenário social e cultural que influencia os meios de produção por elas desempenhados.

Diante desta perspectiva, e compreendendo a importância da agricultura familiar para os municípios da região Oeste de Santa Catarina, identificou-se a necessidade de se conhecer como ocorre a gestão de pequenas propriedades rurais. Desta forma, o presente estudo teve por objetivo apresentar uma proposta de desenvolvimento para a gestão de pequenas propriedades rurais do município de Guatambu (SC), visando contribuir com o fortalecimento econômico, social e familiar, por meio de alternativas de produção.

Para o alcance deste objetivo, elaborou-se um diagnóstico com os dados referentes às propriedades rurais do município pesquisado; identificaram-se suas fragilidades e potencialidades e aplicou-se a matriz de Condicionantes, Potencialidades e Deficiências CPD. Embasados neste diagnóstico, sugeriu-se propostas para o desenvolvimento da gestão destas propriedades.

Considera-se importante conhecer a forma de gestão de pequenas propriedades rurais e efetuar propostas com base nestes dados tendo em vista os possíveis efeitos de uma aplicação de ações voltadas a estes empreendimentos, visando o desenvolvimento territorial do município. Entende-se que a melhoria do processo de gestão de uma propriedade pode constituir-se em medidas que favorecem aspectos econômicos, sociais e no âmbito familiar. A relevância do estudo fica evidente ao pensar que sua aplicação pode ser estendida a outros 
municípios de pequeno porte, já que segundo Meurer e Vieira (2010), dos 5.565 municípios no Brasil, a maioria tem menos de 20.000 habitantes, configurando-se, portanto, em municípios considerados de porte pequeno.

Este trabalho foi estruturado pela ordem introdutória, a revisão bibliográfica para aporte teórico, os procedimentos metodológicos para legitimidade do estudo, seguido pela análise dos dados da pesquisa que resultou em prospecções para o fomento da pequena propriedade rural e, por fim, as conclusões.

\section{Desenvolvimento rural e sustentabilidade}

O desenvolvimento não pode mais ser visto apenas como crescimento econômico. Este conceito foi ampliado à medida que passou a incorporar aspectos relacionados às questões sociais e ambientais de maneira a tornar-se sustentável. De acordo com Lustosa (2010, p. 151), "o desenvolvimento é sustentável ou não é verdadeiro desenvolvimento". Contemplando diversos aspectos da sustentabilidade, entre eles os ambientais, econômicos e sociais, o "desenvolvimento como liberdade" proposto por Sen (2010), significa a retirada das restrições que limitam às escolhas e oportunidades dos indivíduos.

Diante desta expansão do conceito, considera-se que o desenvolvimento sustentável abrange o crescimento econômico, a preservação ambiental, as questões sociais que envolvem a qualidade de vida, a distribuição da renda e ainda os aspectos culturais e políticos (LUSTOSA, 2010). A compreensão deste conceito é de extrema importância, considerando que o entendimento acerca do desenvolvimento é que determina as possibilidades para o alcance do desenvolvimento territorial de maneira sustentável, não bastando apenas aumentar a produção, mas fazendo-se necessário a preocupação com os danos ambientais, os quais podem gerar perdas econômicas no curto e médio prazo (COSTABEBER; CAPORAL, 2003).

Partindo da premissa da busca pela elaboração de estratégias de desenvolvimento, algumas dimensões são imprescindíveis e merecem atenção. Estas dimensões tratam de aspectos ecológicos, econômicos, sociais, culturais, políticos e éticos. Abrangem desde a manutenção, passando pela recuperação e pela preservação dos recursos naturais, da qualidade de vida, dos resultados econômicos, do respeito à cultura local nos processos de desenvolvimento rural e urbano, portanto, territoriais, dos processos participativos e democráticos e da garantia ao pleno exercício da cidadania (COSTABEBER; CAPORAL, 2003). Isto posto, nota-se, portanto, que a agricultura familiar é peça fundamental para o alcance do desenvolvimento rural de maneira sustentável, por seu papel dinamizador da economia e de aporte à configuração cultural e social de um território.

\subsection{A Importância da Agricultura Familiar na região Oeste Catarinense}

No Brasil, a agropecuária desenvolvida sob a óptica familiar possui vital importância na geração de renda, empregos e na produção de alimentos. Este modelo produtivo responde, no país, por mais de $80 \%$ da ocupação no setor rural e representa cerca de $40 \%$ da produção agrícola (CONAB, 2012). Embora a agricultura familiar se caracterize pela diversificação da 
produção e pelo direcionamento para as necessidades de abastecimento da família, sua principal atividade é voltada ao mercado (DORIGON, 2008). De acordo com os estudos da Conab (2012) "a agricultura familiar pode ser entendida como o cultivo da terra realizado por pequenos proprietários rurais, tendo como mão de obra essencialmente o núcleo familiar".

Ainda que heterogênea, o segmento da agricultura familiar representa significativamente a produção agropecuária e o produto gerado pelo agronegócio brasileiro por sua relação entre os importantes elos da cadeia produtiva, ou seja, o inter-relacionamento com importantes segmentos da economia (GUILHOTO et. al., 2007). De acordo com dados da CONAB (2012), as pequenas propriedades rurais são responsáveis pelo abastecimento da mesa dos brasileiros e sua importância para a produção nacional é representada por números de produção como $87 \%$ da mandioca, $70 \%$ do feijão, $46 \%$ do milho, $38 \%$ do café, $34 \%$ do arroz, $21 \%$ do trigo e na pecuária, $60 \%$ do leite, $59 \%$ do plantel de suínos, $50 \%$ das aves e $30 \%$ dos bovinos. Estes alimentos compõem a cesta de consumo presente na alimentação humana, portanto, indispensáveis para a manutenção da saúde.

Com relação à região Oeste Catarinense, esta se caracteriza pela produção baseada na agricultura familiar, responsável pelo impulso do desenvolvimento local e regional, sendo um dos pilares da economia de Santa Catarina. A região concentra a produção agropecuária do Estado o que justifica a dependência econômica destas atividades e sua inter-relação aos demais setores. Entretanto, a realidade regional da agricultura familiar foge de sua lógica estrutural que está, sobretudo, em satisfazer as necessidades de consumo da família (MIOR, 2005). A região possui características diferenciadas advindas do processo de colonização. Relacionando o desenvolvimento econômico do território com a inserção das agroindústrias e a produção familiar o que gerou mudanças significativas nos sistemas de produção e no estilo de vida em decorrência da modernização no campo (BADALOTTI et al, 2007).

De acordo com Konrad e Silva (2012), a capacidade produtiva das agroindústrias locais é assegurada pelas propriedades rurais baseadas na agricultura familiar. Na região as principais atividades agropecuárias desenvolvidas são voltadas a cultivos tradicionais de milho e soja e ao crescente aumento da bovinocultura de leite, predominando as cooperativas de produção agropecuária e a integração com agroindústrias de abate de suínos e aves (WINCK, 2012).

A atividade leiteira teve seu impulso a partir da década de 70, quando a região buscou acompanhar o processo de reestruturação no sistema produtivo, intervindo nas principais atividades pecuárias comerciais desenvolvidas que eram a avicultura e suinocultura, por meio do sistema de integração, caracterizado pela centralização e pelo crescimento da produtividade individual com altos investimentos em equipamentos e infraestrutura na produção. Com isso, alguns produtores não conseguiram acompanhar as exigências destes setores e visualizaram a bovinocultura de leite como alternativa de geração de renda e como forma de assegurar a permanência no meio rural, devido a poucos investimentos iniciais de implantação (ROVER; LANZARIN, 2008).

Diante do exposto, as cooperativas regionais desenvolvem um importante papel na viabilidade econômica e social das famílias com renda proveniente da produção de leite, pois seguem a tendência em remunerar mensalmente o produtor rural, seguindo normas próprias de qualidade, quantidade e manutenção do volume de matéria prima entregue e exigindo dos atores da cadeia de suprimentos sua manutenção e relativa dependência quanto ao valor pago, 
o que intervém em questões econômicas e técnicas e no aprimoramento da produção (WINCK, 2012). A relevância do setor leiteiro está no acesso à qualidade de vida e permanência do produtor no setor agropecuário, impulsionando o desenvolvimento dos municípios, inclusive canalizando renda para o espaço urbano (ROVER; LANZARIN, 2008).

Outro fator propulsor responsável pelo desempenho financeiro das propriedades rurais é creditado ao fomento da integração vertical de aves e suínos. O fato de a agricultura familiar estar submetida a intensos processos de transformação e reestruturação de seus sistemas produtivos, devido à modernização de suas instalações, desencadeou a formação de complexos agroindustriais articulados ao sistema familiar de produção (BADALOTTI et. al. 2007). Para Mior (2005) as propriedades rurais da região encontram na integração agroindustrial maiores perspectivas de êxito.

Em face desta realidade, a agricultura familiar presente no Oeste Catarinense foge de sua lógica estrutural que está, sobretudo, em satisfazer as necessidades de consumo da família (MIOR, 2005), partindo para um modelo produtivo em massa imposto pela agroindústria que introduz mudanças que "[...] não podem ser avaliadas tão somente sob o prisma da produtividade, mas no conjunto de fatores da unidade de produção, a família rural e de suas relações, embates e consequências da acelerada mudança no mundo da produção rural". (BONAMIGO et. al., 2014, p. 2).

\subsubsection{Agropecuária no Oeste Catarinense: matrizes produtivas e processos de integração}

O território do Oeste Catarinense é composto por 118 municípios, representando geograficamente $25 \%$ do total da área do Estado. Destaca-se na atividade agropecuária com cerca de $50 \%$ do valor bruto da produção agrícola e possui uma capacidade de produção de alimentos superior à demanda regional e estadual (MIOR, 2007). Por essa razão, o território é reconhecido como "celeiro" do Estado. A cidade de Chapecó (SC) é considerada o polo regional, concentrando a maior parcela da população e duas das maiores agroindústrias do país.

De certa maneira, a região mostra dependência econômica das indústrias agroalimentares, seja por suas atividades comerciais ou de serviços (direta ou indiretamente) ligados ao setor (DORIGON, 2008). O resultado desta relação apresentou nas últimas décadas o maior número de indústrias de carnes de suínos e de aves instaladas da América Latina. (BONAMIGO et al, 2014).

O sistema de parceria ou integração firmado pelas agroindústrias é realizado por meio de contratos, que passam por modificações contínuas e que resultam em um processo rígido e articulado entre os elos (KONRAD; SILVA, 2012). Neste processo, as agroindústrias fornecem os subsídios para a produção e garantem a compra dos lotes de animais, enquanto os agricultores ficam responsáveis pelos investimentos de instalação e pela mão de obra componente neste sistema. Este modelo de produção via integração modificou substancialmente a vivência no ambiente rural, impondo novas relações (ROVER; LANZARIN, 2008). 
Inicialmente, este modelo produtivo garantiu à agricultura familiar benefícios como a comercialização ampliada de seus recursos. Porém, nas últimas duas décadas passou a introduzir o uso da tecnologia e a aceleração da produtividade, o que tornou essa relação viável apenas para a indústria (KONRAD e SILVA, 2012). Para Rover; Lanzarin (2008), o produtor rural passou a perder seu poder de decisão sobre suas atividades. Conforme Bonamigo et. al. (2014, p. 02), "Essa alteração teve várias implicações, tais como a perda da autonomia no processo produtivo dos agricultores, a concentração da produção e a consequente exclusão de produtores e o agravamento de problemas ambientais". Paralelo a estes fatores impostos pela agroindústria, a pobreza no meio rural e a crise do setor agropecuário se refletem na exclusão social das famílias que habitam a região, influenciando, consequentemente, o êxodo rural e no aumento da periferia urbana (BADALOTTI et al, 2007).

Neste cenário, a permanência dos agricultores nas cadeias tradicionais de produção suinocultura, avicultura, grãos e, sobretudo, leite são fundamentais para a inserção em escala no mercado e para a obtenção de um patamar mínimo adequado para a renda destes agricultores (MIOR, 2007). Em contrapartida, ainda segundo Mior (2007), o ambiente da propriedade rural destaca-se como o melhor território para desenvolver novas oportunidades econômicas sucedidas da agricultura tradicional o que assegura a inserção no mercado e a permanência no campo. Contudo, há necessidade de se implantar novas opções econômicas que viabilizem as pequenas propriedades rurais (DORIGON, 2008).

Observando esta necessidade, diversas atividades produtivas voltadas para a subsistência familiar podem ser empregadas como alternativa de renda e como mecanismo para oportunizar a competitividade da propriedade no mercado de consumo e, desta forma, estimular a permanência no espaço rural. Alguns exemplos destas atividades produtivas são o cultivo de batata-doce, cana de açúcar, mandioca, arroz, entre outras opções de cultura ou até mesmo produtos derivados da agricultura familiar como queijo artesanal, pão caseiro, derivados de carne e leite, comercializados diretamente aos consumidores.

Neste cenário, pode se conceber que estas atividades agrícolas diferenciadas elencam um modelo de gestão de pequenas propriedades rurais que visa contribuir para o fortalecimento econômico, social e familiar por meio de alternativas de produção.

\subsubsection{Agricultura familiar e sustentabilidade}

Os debates embasados no desenvolvimento sustentável e na geração de emprego e renda têm impulsionado a discussão acerca do papel e importância da agricultura familiar (GOMES, 2004). As principais características da agricultura familiar são: a) o fato de a família ser responsável pela geração de valor e b) este tipo de agricultura ser o maior produtor de alimentos, integrando a produção e o consumo de alimentos (ANDREOLI, 2008).

Inúmeras são as dificuldades encontradas pela agricultura familiar. Loch (2009) destaca o problema da geração de renda, que tem como consequência a falta de emprego e o aumento da produção em escala industrial. Este fator diminui a competitividade dos pequenos agricultores familiares e como consequência tem-se o êxodo rural, causando problemas econômicos e sociais, inclusive no ambiente urbano. Outra limitação centra-se na produção de 
uma única cultura. Para Andreoli (2008) a monocultura é um problema para o agricultor familiar, pois o trabalho da família deve gerar renda durante todo a ano.

Buscar desenvolver a agricultura familiar de forma sustentável é uma alternativa para minimizar estes problemas. Gomes (2004) vincula a sustentabilidade à capacidade de conservação ou aumento da qualidade de vida, bem como a garantia de recursos para as próximas gerações por parte dos agricultores familiares, no entanto, destaca a dificuldade e complexidade em determinar a sustentabilidade de qualquer atividade. A agricultura familiar, segundo Costabeber e Caporal (2003), demonstra maior capacidade em atender aspectos relativos à conservação dos recursos naturais e da biodiversidade, atividades artesanais com baixo impacto ambiental e relevância social, entre outros.

Alternativas para aumentar o valor agregado dos produtos e, consequentemente, a renda do produtor está na industrialização e comercialização, no aumento da qualidade na produção e, ainda, na integração de atividades econômicas como o turismo (ANDREOLI, 2008). Um modelo de gestão que leve em consideração todas as características inerentes à pequena propriedade rural é fundamental para aplicação destas estratégias de geração de renda.

2.2 Modelo de Gestão para a pequena propriedade rural do Oeste Catarinense

Considerando que a produção da região Oeste está baseada nas agroindústrias localizadas em seu território, uma constatação que se evidencia é a perda de competitividade regional estabelecida em função do "esgotamento" destes arranjos produtivos oriundos de fatores ambientais, da estagnação dos clusters agroindústrias e até mesmo da mudança de sua infraestrutura para regiões mais vantajosas (BADALOTTI et al, 2007). Neste ambiente, justifica-se o desenvolvimento de um modelo gestão que atenda as necessidades da pequena propriedade rural em virtude de sua importância ao desenvolvimento local e ao abastecimento de alimentos a centros urbanos.

Um modelo de gestão voltado à agricultura familiar depende de fatores sistêmicos que envolvem aprendizado organizacional, liderança e inovação com vistas à busca de resultados e a aplicabilidade depende de como será desenvolvido. (MARTINS, 2014). De acordo Mior (2005) a gestão integrada da propriedade rural está baseada na visão multidisciplinar e sustentabilidade econômica.

Propor uma efetiva gestão das propriedades rurais de forma sustentável é importante, porque o pequeno produtor rural catarinense participa ativamente da economia, relacionando entidades e diversos atores pertencentes à agricultura familiar do Estado. Cabe, neste sentido, a sociedade e as organizações não governamentais, levar à pequena propriedade rural informações, conhecimento e tecnologias para seu desenvolvimento competitivo (MIOR, 2005). A relevância das pequenas propriedades rurais para o desenvolvimento sustentável do território está atrelada ao desenvolvimento de técnicas produtivas mais equilibradas, como a diversificação de cultivo, o menor uso de insumos industriais e a preservação do patrimônio genético (CONAB, 2012).

Assim, mostra-se como fundamental manter e fortalecer a produção tradicional vinculada à agricultura familiar e a pequena propriedade. Martins (2014, p. 02) aponta que 
"novas metodologias de gestão nas unidades familiares favorecem melhores condições para a sua inserção nos mercados e, consequentemente, para a geração de rendas pelas famílias de agricultores".

A busca pela construção de alternativas que visem um modelo de gestão para a pequena propriedade rural parte do princípio da sustentabilidade para garantir a permanência destas famílias no campo, diminuindo o êxodo rural. Contudo, para que haja continuidade na pequena propriedade é necessário relacionar a agricultura familiar com órgãos geradores de conhecimento, pesquisa, extensão rural e de fomento (MARTINS, 2014). A fim de inspirar e alavancar alternativas de produção e de organização que impulsionem o desenvolvimento regional sustentável, com base na agricultura familiar.

\begin{abstract}
Junto com isso, pensar em ocupações e empreendimentos rurais não agrícolas como uma forma de viabilizar a própria agricultura familiar e, por extensão, o território rural. A questão fundamental é verificar se estão sendo propostas e ou efetivadas políticas e projetos voltados ao aumento da atratividade destes municípios, especialmente na perspectiva dos jovens e das mulheres. Fundamental é pensar sobre o capital social do território porque a confiança, a cooperação, a solidariedade e a responsabilidade cívica, juntamente com o sentimento de pertencimento, serão os pilares do desenvolvimento territorial sustentável (PTDRS, 2010).
\end{abstract}

Segundo Dorigon (2008) opções não agrícolas devem ser analisadas para implantação de um modelo de gestão na pequena propriedade para assim assegurar a estabilidade econômica familiar. Estas opções podem ser advindas do turismo rural, da constituição de indústrias, da prestação de serviços no meio rural e da agregação de valor dos produtos oriundos do território. Além disso, alternativas de atividades produtivas de culturas tradicionais se encaixam em um modelo produtivo a este estrato de agricultores, como a produção de frutas, hortaliças, ovinos, caprinos, peixes, mel, entre outras atividades que permitem agregar valor por meio da diferenciação do produto ou mesmo a industrialização. Buscar um posicionamento baseado na diferenciação e na valorização da origem, o próprio Oeste, da procedência e do tipo de produção a pequena propriedade rural, como a imagem "colonial" ou mesmo do agroecológico ou orgânico, em um contexto de segmentação do mercado podem se configurar em oportunidades aos pequenos produtores (DORIGON, 2008).

Em relação às culturas permanentes, sua relevância econômica torna fundamental a manutenção das famílias no campo, o que necessita é estabelecer agregação de valor. No entanto, deve ser levado em conta esforços para conversão aos sistemas orgânicos e no caso específico do leite, a produção a base de pasto por meio do sistema rotativo (PTDRS, 2010).

No contexto econômico, a pequena propriedade rural desempenha um elemento necessário ao desenvolvimento sustentável dos municípios e, consequentemente, de sua população. Desta forma, justifica-se a valorização da agricultura familiar, bem como o incentivo a permanência no campo por meio de um modelo de gestão que atenda as necessidades especificas ao desenvolvimento do território. 


\section{Procedimentos Metodológicos}

O presente estudo foi desenvolvido no município de Guatambu, situado no Oeste de Santa Catarina. A escolha ocorreu tendo em vista que a maior parcela de sua população ocupa áreas rurais.

A abordagem utilizada na pesquisa foi qualitativa, já que este estudo busca compreender o significado que os indivíduos atribuem a um determinado problema social ou humano (CRESWELL, 2010). Uma das principais vantagens na utilização do método qualitativo está no fato de que geram informações detalhadas, as quais "mantém intactas as perspectivas dos participantes" (GUIMARÃES et. al., 2004, p. 82).

A pesquisa teve como enfoque o estudo de caso, abordando aspectos relevantes da agricultura familiar do município. Segundo Creswell (2010), no estudo de caso o pesquisador examina com profundidade eventos, processos, indivíduo ou grupo de indivíduos. Para Yin (2010) trata-se de uma investigação empírica, realizada através de um conjunto de procedimentos. Vergara (2013) destaca o caráter de profundidade e detalhamento inerente ao estudo de caso.

Classifica-se como um estudo descritivo, caracterizando-se por descrever um fenômeno e sendo utilizado para identificação, avaliação e descrição de um problema (COLLIS; HUSSEY, 2005). Segundo Vergara (2013), a pesquisa descritiva apresenta aspectos de uma população ou fenômeno, permitindo estabelecer correlações entre as variáveis.

Para a coleta de dados primários foram realizadas entrevistas com o gestor da Secretaria Municipal de Agricultura - SMA e técnicos da Empresa de Pesquisa Agropecuária e Extensão Rural de Santa Catarina - EPAGRI. Uma vantagem da entrevista é sua adaptabilidade, possibilitando desenvolver e esclarecer as respostas (BELL, 2008). Os entrevistados foram selecionados devido a sua colaboração para o desenvolvimento da pesquisa, em função de sua atuação em áreas estratégicas no que se refere à questão agrícola no município de Guatambu (SC).

Paralelamente ocorreu a aplicação de questionário com proprietários de pequenas unidades familiares. A seleção da amostra foi por conveniência. Para Vergara (2013, p. 47) esta forma de escolha de amostra "longe de qualquer procedimento estatístico, seleciona elementos pela facilidade de acesso a eles". A amostra compreendeu 07 famílias de um total de 21 propriedades consideradas inovadoras, correspondendo a 33\% do universo de estudo. Nesta etapa não foi possível entrevistar mais famílias em função da dificuldade de acesso (por se tratar de meio rural) e pela disponibilidade de tempo para realização da pesquisa.

Também foram coletados dados secundários por meio de pesquisa documental. Esta investigação buscou identificar e caracterizar o município estudado. Os dados secundários sobre o município foram obtidos através dos elementos informados pelo Atlas do desenvolvimento e sites da FIRJAN, FECAN, IBGE, entre outros. Dentre as vantagens da utilização de documentos como fonte de pesquisa está o fato de serem estáveis, podendo ser revisados inúmeras vezes, exatos e de ampla cobertura (YIN, 2010).

A fase inicial da pesquisa documental é definida por Godoy (1995) como pré-análise, contempla a seleção, organização e uma leitura "flutuante" do material. A segunda fase trata 
da exploração dos documentos, compreende uma leitura mais aprofundada, bem como os procedimentos de codificar, classificar e categorizar o material (GODOY, 1995).

Para análise e sistematização dos dados foi utilizada a metodologia de Condicionantes, Potencialidades e Deficiências - CPD. A referida ferramenta destaca-se na utilização da matriz de elaboração do Plano Diretor, inclusive do ambiente rural de municípios. Dentre as vantagens da metodologia pode-se citar a possibilidade de apresentação gráfica, o que facilita a transmissão dos resultados de sua aplicação (BLUMENAU, 2008). A Matriz CDP, ao ser aplicada no planejamento urbano considera os seguintes aspectos:

- Condicionantes - Elementos de estrutura urbana (e rural) que devem ser mantidos, preservados ou conservados e, sobretudo, considerados no planejamento. São, basicamente, os elementos do ambiente urbano (e rural) e natural, ou planos e decisões existentes, com consequências futuras previsíveis no ambiente físico ou na estrutura urbana, que determinam a ocupação e o uso do espaço municipal.

- Deficiências - Situações que devem ser melhoradas ou problemas que devem ser eliminados. São situações negativas para o desempenho das funções da cidade e do município, e que significam estrangulamentos de caráter qualitativo e quantitativo para o desenvolvimento da área em estudo e da sua comunidade.

- Potencialidades - Elementos, recursos ou vantagens que podem ser incorporados positivamente ao sistema territorial e que até entãonão foram aproveitados adequadamente. (PREFEITURA MUNICIPAL DE BLUMENAU, 2008, p.7).

Apesar de "historicamente utilizada por planejadores para diagnosticar áreas urbanas" (BLUMENAU, 2008, p.6), não foi possível identificar na literatura casos de aplicação e utilização desta mesma metodologia da matriz no planejamento rural ou desenvolvimento rural, constituindo-se uma atipicidade neste estudo. A próxima seção traz a apresentação dos dados bem como sua análise e discussão.

\section{Análise dos Dados da Pesquisa}

Esta seção é composta pela análise dos dados primários e secundários da pesquisa, bem como a apresentação da matriz CPD, listando os fatores Condicionantes, Potencialidades e Deficiências do município estudado. Por meio do levantamento destes dados juntamente com o conhecimento empírico e o teórico chegou-se a proposta de um modelo de gestão para pequenas propriedades rurais, a fim de impulsionar o desenvolvimento territorial.

\subsection{Análise dos dados secundários}

Com relação à análise dos dados secundários, foi possível observar que a distribuição da população total residente é de 4679 habitantes. Esta se distribui de forma desigual no ambiente municipal, uma vez que 2930 habitantes residem no ambiente rural e os demais 1749 habitantes no espaço urbano (IBGE, 2012). No que diz respeito aos aspectos econômicos do município, o Atlas do Desenvolvimento Humano (2014) apresenta dados sobre o percentual de pessoas ocupadas, sendo que ocorreu uma diminuição no setor agropecuário, de $68,46 \%$ no ano de 2000 , para 49,54\% em 2010, o que confirma a seletividade deste setor produtivo, atestada na revisão da literatura da pesquisa. 
A esta informação, o Atlas do Desenvolvimento Humano (2014), acrescenta também a renda per capita média da população de Guatambu, que em 2010 foi de $\mathrm{R} \$$ 687,32 e de $\mathrm{R} \$ 274,53$ reais em 2000, representando um crescimento de 200,4\%. Destaca-se ainda, o rendimento médio dos ocupados, em 2010, que foi de $\mathrm{R} \$ 1055,85$, ou seja, uma variação de $384,7 \%$. Outro dado relevante sobre o município e publicado no Atlas do Desenvolvimento Humano (2014) refere-se ao Índice de Desenvolvimento Humano do Município - IDHM, que passou de 0,389, portanto considerado muito baixo, no ano de 1991, para 0, 717 em 2010 posição ponderada como média. A evolução deste índice do município aponta prováveis melhorias no período no que se refere à qualidade de vida da população (educação, longevidade e renda).

Outra fonte de dados consultada para a elaboração do diagnóstico do município de Guatambu refere-se aos dados publicados pela FIRJAM, por meio do Índice Firjan de Desenvolvimento Municipal (IFDM). Este sistema de pesquisa verifica anualmente o desenvolvimento socioeconômico dos municípios e utiliza como fonte de dados as bases estatísticas públicas oficiais dos Ministérios do Trabalho, Saúde e Educação. O índice IFDM, “[...] varia de 0 (mínimo) a 1 ponto (máximo) para classificar o nível de cada localidade em quatro categorias: baixo (de 0 a 0,4$)$, regular $(0,4$ a 0,6$)$, moderado (de 0,6 a 0,8$)$ e alto $(0,8$ a 1) desenvolvimento. Ou seja, quanto mais próximo de 1, maior o desenvolvimento da localidade" (FIRJAM, 2014).

Os dados gerais do FIRJAN (2014) de Guatambu também indicam que o índice de desenvolvimento do município IFDM alcança o índice de 0,7255; de emprego e renda 0,6192; de educação 0,7317 e saúde 0,8256 . Outra análise possível tomando-se estes dados consiste no menor índice apresentado pelo município, referente ao emprego e a renda, segmento em que está centrada esta pesquisa. Estes indicadores demonstram a necessidade de maior aporte de políticas públicas e de iniciativas dos próprios produtores, para a motivação do trabalho e da renda no município.

Em relação ao ranking que classifica os municípios brasileiros, os dados da FIRJAM (2014) usados como referência para o ano de 2011, apontam o município de Guatambu na posição $1.208^{\circ}$ em nível nacional e $145^{\circ}$ no estado de Santa Catarina. O posicionamento no ranking aponta a necessidade de evolução dos aspectos avaliados relacionados às variáveis que compõem o índice (educação, saúde e renda).

Também se utilizaram para esta pesquisa, as informações disponibilizadas pela Federação Catarinense das Associações Municipais - FECAM - que possui como objetivo representar o interesse dos municípios Catarinenses, além de desenvolver produtos e serviços para melhoria da eficiência na gestão pública municipal (FECAM, 2014). Os dados publicados pela FECAM (2014) apontam que Guatambu possui uma remuneração média dos trabalhadores formais de $\mathrm{R} \$ 1.159,36$ e que o índice de evolução dos empregos formais no último triênio foi negativo $(-5,44)$, ou seja, o município teve uma diminuição dos empregos formais nos últimos três anos, fator preocupante se considerado que foi um período de crescimento da economia regional. Em relação aos aspectos econômicos do município, constata-se um Produto Interno Bruto - PIB per capita de R \$ 32.727,13 e uma evolução média de $15,8 \%$ no último triênio (FECAM, 2014). 
Quanto aos dados das lavouras temporárias do município em área plantada apontam a soja e o milho e como as principais culturas, o trigo, o feijão, a cana de açúcar, o fumo e a lavoura permanente da erva mate. Com bases no ranking das culturas percebe-se que não há uma diversificação expressiva dos sistemas produtivos. Na pecuária destaca-se a avicultura, a suinocultura, a bovinocultura de corte e leiteira (IBGE, 2012).

\subsection{Análise dos dados primários}

Após a análise dos dados secundários foram coletados dados primários, elaborados por meio de entrevistas na esfera pública e questionários aplicados em pequenas propriedades rurais do município de Guatambu (SC). Nas entrevistas com os gestores da Secretaria Municipal de Agricultura e Empresa de Pesquisa Agropecuária e Extensão Rural de Santa Catarina - EPAGRI - pode se observar que os dois órgãos procuram atender o pequeno agricultor de forma conjunta. Ambos estão localizados na mesma estrutura física e compartilham as políticas públicas de apoio aos agricultores, tanto municipal quanto estadual. Verifica-se a complementação do trabalho desenvolvido pelas entidades e o diálogo entre os mesmos, sendo que as atividades são voltadas à agricultura familiar, como dias de campo, palestra e feiras.

Sobre a aplicabilidade de um modelo de gestão de propriedade rural com propostas de diversificação de culturas ou outras fontes de renda que promovam o desenvolvimento, bemestar e sucessão familiar é notável o interesse destes órgãos ao incentivo de alternativas que visem traçar estes propósitos. Porém, relatam a dificuldade de proporcionarem aos agricultores eventos e similares, devido à rotina em suas atividades ou até mesmo por questões culturais.

Os entrevistados creditam ao risco de produção, o clima, a variação de preços de insumos, bem como sua venda como vetores limitantes ao agricultor familiar no momento de investir em outros cultivos ou novas fontes de renda. Além disso, o gestor público municipal da Secretaria da Agricultura menciona o fato de não ter recursos fixos para incentivos de projetos deste fim, o que se constitui como um fator limitador de variáveis que deixam de ser demonstradas ao pequeno produtor rural como fonte de renda.

Estes fatos retratam as condicionalidades das pequenas propriedades rurais como limitante de permanência no campo. Os desafios são maiores que as perspectivas, o que justifica um trabalho em parcerias entre governos, com instituições, pois, nestas pequenas propriedades são produzidos os alimentos balanceados e essenciais ao consumo humano. No caso das pequenas propriedades rurais de Guatambu esta é uma parcela considerável da economia do município, já que a população se encontra, de forma mais expressiva, no ambiente rural.

Em ações de aporte para novas fontes de renda, os entrevistados relataram que as ações realizadas para a apresentação de novas culturas, para o desenvolvimento do ambiente rural, como exemplo a produção de frutas, contou com pequeno número de expectadores, ou seja, não houve retorno na participação por parte dos agricultores. As atividades que contam com maior número de participantes são voltadas a pecuária de leite, abrangendo pequenos, médios e grandes produtores, como exemplo, os dias de campo e a feira EXPOLEITE. 
A análise das atividades realizadas pelas entidades não abrangem alternativas variadas de produção, a não ser a atividade leiteira e hortifruticultura, o que destaca a necessidades de trazer principalmente a pequenas propriedades rurais novas opções de cultivo voltadas ao aumento de renda.

A perspectiva do futuro da agricultura familiar está na permanência do jovem no espaço rural. Segundo os entrevistados, as linhas de crédito aumentaram, mas a burocracia impede que esteja disponível aos jovens. Desta forma, a sucessão familiar se torna o grande desafio para o município, em função da possibilidade do comprometimento da produção, no futuro, inclusive a carência de mão de obra para as atividades agrícolas.

A pesquisa levantou dados relevantes das condicionalidades das famílias que possuem condições de ser elencada como modelo de desenvolvimento de gestão. O universo estudado, conta com propriedades que variam de três a catorze hectares de tamanho. A renda destes agricultores varia entre um salário mínimo e mais de quatro salários mínimos, advinda na produção comercial, por integração ou parcerias com agroindústrias da região.

Referente à produção comercial, observa-se que o leite é a principal atividade desenvolvida. $\mathrm{O}$ fator propulsor desta atividade pode ser atrelado à demanda de mercado, maior que a oferta e o pagamento pela matéria prima mensal, diferente de outras atividades agrícolas que dependem de recursos naturais para ser comercializada, como exemplo, o plantio de sementes, ou ainda o clico de desenvolvimento de bovinos de corte. Assim o pagamento varia de acordo com o tempo de produção, ocorrendo em períodos maiores, não permitindo ao agricultor fazer um planejamento ordenado de suas ações.

Pode-se constatar ainda, que as pequenas propriedades são advindas de herança ou aquisição. Um dos motivos deste estacionamento da área produtiva está nos valores das terras, pois, nos últimos anos, percebeu-se um aumento de valor de áreas aptas para a produção. Um fator que influencia no aumento do valor da terra é a proximidade da cidade de Chapecó, polo regional.

Em relação aos fatores ambientais das propriedades rurais, verificou-se a questão da legislação vigente quanto à reserva legal da propriedade, pois independente de seu tamanho e localização se faz obrigatória e os agricultores entendem como um fator restritivo importante à produção. Entretanto, de forma geral, os entrevistados atendem aos quesitos legais ambientais. Sobre o tema, o estudo abordou o uso de adubação orgânica ou química, uso de agrotóxico e destino das respectivas embalagens e sobre o destino do lixo orgânico e reciclável. Contataram-se as limitações de informações aos produtores, por não saberem a utilização correta destes elementos.

Em relação à sanidade da propriedade, um fator que chama atenção é a questão da instalação de fossas sépticas, sendo que nenhuma delas conta com este atributo, logo, desconhecem os riscos relacionados à contaminação de produtos, animais e à sua própria saúde.

Um dos pontos da pesquisa referiu-se a parte técnica da propriedade, ou seja, a participação dos órgãos municipais e estaduais na assistência, implantação e acompanhamento das atividades desenvolvidas ou a serem implementadas. Entretanto, percebe se que há distanciamento entre os atores. É um fato importante para os estudos, pois, relacionam a não participação dos produtores por não verificarem aplicabilidade no interior da 
propriedade. Relatam que eventos municipais estão voltados ao médio e grande produtor, portanto, não aos pequenos agricultores.

\subsubsection{Matriz Condicionantes Potencialidades e Deficiências}

Com base nos dados coletados e com o intuito de alcançar o objetivo principal da pesquisa, foi desenvolvida a Matriz de Condicionalidades, Deficiências e Potencialidade $\mathrm{CPD}$, em relação à realidade das propriedades pesquisadas. A Matriz CPD que consiste no desenvolvimento e classificação dos elementos estruturais do espaço territorial foi adaptada ao ambiente rural do município de Guatambu (SC), pelo fato de apresentar diversas vantagens, já legitimadas no que se refere ao planejamento urbano. 
Tabela 1: Matriz Condicionantes, Potencialidades e Deficiências - CPD

\begin{tabular}{|c|c|c|c|c|}
\hline Subdimensão & Condicionantes & Potencialidades & Deficiências & Medidas interventivas \\
\hline $\begin{array}{l}\text { Desenvolvimen } \\
\text { to econômico } \\
\text { das pequenas } \\
\text { propriedades; }\end{array}$ & $\begin{array}{l}\text {-Adversidades } \\
\text { climáticas; } \\
\text {-Extensa área } \\
\text { geográfica } \\
\text { municipal; }\end{array}$ & $\begin{array}{l}\text {-Maior parte da população } \\
\text { do município se encontra na } \\
\text { área rural; } \\
\text {-O município possui } \\
\text { profissionais especializados } \\
\text { para capacitação e } \\
\text { treinamento das famílias; } \\
\text {-Acesso asfáltico municipal; } \\
\text {-Localização privilegiada, } \\
\text { quanto à proximidade de } \\
\text { Chapecó que facilita a } \\
\text { comercialização de } \\
\text { produtos; própra } \\
\text {-Solo prio para } \\
\text { diversificação de culturas; } \\
\text {-O município possui parque } \\
\text { nacional ambiental; } \\
\text {-Propriedades rurais com } \\
\text { belezas naturais, como } \\
\text { vegetação nativa, cachoeira } \\
\text { e trilhas. } \\
\text {-Propriedades purais } \\
\text { localizadas próximas ao } \\
\text { lago artificial de hidrelétrica } \\
\text { que pode ser utilizado para } \\
\text { atividades náaticas, } \\
\text { obedecendo à legislação } \\
\text { ambiental para este fim } \\
\text { (PACUERA). }\end{array}$ & $\begin{array}{l}\text {-Carência de conhecimentos } \\
\text { tecnológicos; } \\
\text {-Falta de sucessão familiar; } \\
\text {-Falta de acesso às } \\
\text { informações; } \\
\text {-Falta de acesso ao credito } \\
\text { para as pequenas } \\
\text { propriedades familiares; } \\
\text {-Carência de diálogo entre } \\
\text { órgãos técnicos e pequenos } \\
\text { agricultores; de } \\
\text {-Poucas alternativas de } \\
\text { comunicação e informação ao } \\
\text { meio rural, como jornais, } \\
\text { internet, telefone, entre } \\
\text { outras. estradas } \\
\text {-Manutenção das estrado } \\
\text { rurais e acessos precários, } \\
\text { bem como a sinalização; } \\
\text {-Falta de perspectivas aos } \\
\text { jovens do meio rural; } \\
\text {-Poucas variedades de } \\
\text { produtos para } \\
\text { comercialização; } \\
\text {-Desvalorização dos produtos } \\
\text { locais; a ass } \\
\text {-Poucas associações } \\
\text { cooperativas } \\
\text { comercialização de produtos; } \\
\text {-Pouca estrutura em saúde às } \\
\text { famílias do espaço rural; } \\
\text {-Falta de infraestrutura e } \\
\text { incentivo ao turismo, como: } \\
\text { hotel, pousada. }\end{array}$ & $\begin{array}{l}\text {-Fazer reuniões trimestrais com o Conselho Municipal de Agricultura } \\
\text { para promover a comunicação entre as esferas governamentais e não } \\
\text { governamentais. } \\
\text {-Desenvolver ações focadas a pequenos agricultores para geração de } \\
\text { renda, como: palestras, oficinas que demonstrem a viabilidade de uma } \\
\text { nova atividade produtiva; } \\
\text {-Incentivar o trabalho da mulher agricultora para impulsionar a renda; } \\
\text {-A EPAGRI e SMA devem orientar e capacitar os pequenos agricultores } \\
\text { na operacionalização e comercialização de produtos, seja de forma } \\
\text { individual ou associações ou cooperativas; } \\
\text {-Estimular a produção de artesanato e produtos coloniais; } \\
\text {-Dispor as pequenas propriedades rurais estrutura adequada de acesso e a } \\
\text { benfeitorias sem ou com subsidio dos custos operacionais; } \\
\text {-Buscar parceria com outros órgãos afins, como o governo federal, } \\
\text { apontando recursos financeiros para a construção e reforma de moradias } \\
\text { rurais. } \\
\text {-Desenvolver projetos e disponibilizar materiais publicitários de } \\
\text { incentivo ao turismo e como desenvolver; } \\
\text {-Trabalho conjunto das Secretarias Municipais e órgãos afins, para } \\
\text { desenvolver ações de educação ambiental, segurança, violência, saúde, } \\
\text { atividades culturais e esportivas, através de folders, oficinas praticas, } \\
\text { entre outros; } \\
\text {-Promover a consciência ecológica dos produtores atendendo as normas } \\
\text { vigentes; } \\
\text {-Fomentar o cultivo de produtos orgânicos e outras atividades produtivas } \\
\text { como alternativa de renda; } \\
\text {-Buscar ampliar o sinal de telefonia móvel, internet e outras a fim de } \\
\text { melhorar a comunicação e informação dos produtores; } \\
\text {-Criar um modelo de pequena propriedade rural que apresente uma } \\
\text { diversidade de culturas viáveis e adaptadas à região, para evitar riscos } \\
\text { produtivos, buscando incentivar novos produtores a ter alternativas de } \\
\text { renda e manter se no campo e incentivando a sucessão familiar. } \\
\text {-Incentivar a redução do uso de agrotóxico; } \\
\text {-Orientar os agricultores quanto ao manejo e conservação de solos e }\end{array}$ \\
\hline
\end{tabular}




\begin{tabular}{|l|l|l|l|}
\hline & & -Baixa eficiência no processo & águas; \\
& produtivo & -Orientar os agricultores quanto à adubação de cobertura para proteger o \\
& -Falta de orientações quanto & solo, assim como a descompactação do solo para sua possível correção; \\
& ao manejo e fertilidade do & -Orientar boa pratica da recomposição da matéria orgânica; \\
& solo; & -Desenvolver lei municipal para reduzir o uso de agrotóxicos, \\
& -Falta de legislação municipal & incentivando o controle biológico e natural de pragas e doenças; \\
& referente ao uso de & -Incentivar a implantação de agroindústrias de processamento mínimo; \\
& agrotóxicos; & -Adequar, readequar e realizar manutenção de estradas e pontes. \\
\hline
\end{tabular}

Fonte: Os autores 


\section{Prospecções}

Com a finalidade de responder aos objetivos da pesquisa, foi realizado um levantamento de sugestões para diversificação de culturas a ser desenvolvidas por propriedades rurais com a finalidade de impulsionar a renda monetária destas famílias e construir um modelo de gestão para pequenas áreas rurais.

Por meio do diagnóstico tornou-se possível identificar algumas necessidades destas pequenas propriedades. Uma questão de relevância no ambiente rural está relacionada ao bem estar, neste sentido cabe a Prefeitura Municipal, em parceria com os agricultores familiares, realizar ações de incentivos para melhoria de vida no campo.

Para dar início é de suma importância que as estradas de acesso a estas propriedades sejam revistas, pois se encontram em mau estado de conservação. Em relação à informação no campo, são poucas as comunidades rurais que possuem acesso a outros meios alternativos de comunicação, como exemplo a internet, sinal de celular, entre outros. Desta forma, possibilitariam aos jovens do interior maior inserção social, bem como trazer a propriedade novas fontes de tecnologia e informação.

Um fator latente nas áreas visitadas está voltado à habitação, a maior parte das casas é de construções mistas antigas, não oferecendo conforto adequado. Neste aspecto, a Prefeitura Municipal, poderia buscar parcerias com o sindicato rural para desenvolver projetos habitacionais acessíveis para melhorar a qualidade e vida desta parcela da população.

Também como proposta de ação, sugere-se o desenvolvimento de ações conjuntas entre Estado e Município para proporcionar conhecimentos voltados a novas culturas, como: apicultura, horticultura e olericultura, piscicultura, entre outras. Estas são maneiras de fomentar agricultores a buscar alternativas de renda viáveis a pequena propriedade ou até mesmo de melhorar as atividades já existentes como a pecuária, suinocultura e outras.

Também, ressalta-se a necessidade dos próprios agricultores serem mais receptivos às inovações, seja em forma de conhecimento de realidades distintas e que sejam exemplo de sucesso, bem como de maior integração com a estrutura técnica das instituições públicas, a realização de atividades associativas, organização de grupos, para a obtenção de ganhos de competitividade, entre outras.

\section{Conclusão}

Os dados obtidos por meio dos levantamentos realizados conduzem a constatação de que há uma importante relação entre a pequena propriedade rural e a manutenção socioeconômica da região ao fornecer aos clusters agropecuários, no caso na produção de aves, suínos e leite, a matéria prima para sua existência.

Paralelamente, ocorre a discussão acerca do modo de vida destes agricultores que foram bruscamente alterados pela aceleração produtiva das cadeias impostas pela agroindústria. Tendo por base os dados da pesquisa, observa-se que a realidade do município se assemelha com a literatura e aponta a necessidade da construção de um modelo de gestão para o desenvolvimento da pequena propriedade fundamentando-se nos princípios da 
sustentabilidade, visando garantir a permanência destas famílias no campo e diminuindo assim, o êxodo rural.

As circunstâncias da pequena propriedade rural do município de Guatambu (SC) não se desvinculam da realidade do país quando se trata da saída do jovem do campo, ou seja, a sucessão familiar na agricultura está comprometida. Nota-se que conforme a atividade principal da propriedade, dependendo das circunstâncias e da necessidade de assegurar ou não uma renda familiar condizente a suas necessidades de consumo, pode constituir-se em fator indispensável para que se dê continuidade à agricultura familiar e a permanência no campo.

Confrontando os dados da pesquisa constatou-se que a não há um consenso entre o que as entidades entendem como prioridades e a realidade dos produtores. Para desenvolver um modelo eficiente de gestão deve haver maior diálogo entre os mesmos. Desta forma, com o diagnóstico realizado espera-se que os órgãos do setor possam realizar um trabalho conjunto para amenizar os impactos no ambiente rural. Destaca-se a importância de manter e fortalecer a produção tradicional vinculada à agricultura familiar e a pequena propriedade.

Repertoriar o fato de o pequeno agricultor rural atuar de forma significativa na economia do município e sua importância na demanda de produtos para a alimentação diária da população justifica a implementação estratégica de um modelo de gestão para sustentabilidade e desenvolvimento do território por meio dos diversos atores relacionados à agricultura familiar.

Neste estudo, uma limitação percebida foi à dificuldade de acesso para contatar as famílias por tratar-se do meio rural. Outro fator limitador foi o tempo disponível para realização da pesquisa. Para pesquisas futuras sugere-se a ampliação da amostra para abranger uma parcela maior da população, bem como a aplicação das propostas apresentadas neste estudo em uma propriedade, como um projeto-piloto.

\section{REFERÊNCIAS}

AMOSC. Municípios da AMOSC. Disponível em: http://www.amosc.org.br/home/?. Acesso em: 13 jun. 2014.

ANDREOLI, AntonioInácio. Agricultura familiar e sustentabilidade ambiental.Revista Espaço Acadêmico, $n^{\circ}$ 89, out, 2008. Disponível em http://www.espacoacademico.com.br/089/89andrioli.htm. Acesso em: 24 fev. 2015.

ATLAS DO DESENVOLVIMENTO HUMANO. IDMH. Disponível em: http://www.atlasbrasil.org.br/2013/. Acesso em: 13 jun. 2014.

BELL, Judit. Projeto de pesquisa: guia para pesquisadores iniciantes em educação, saúde e ciências sociais. 4. ed. Porto Alegre: Artmed, 2008.

BLUMENAU. Blumenau 2050 - Cidade de Blumenau. Revista de Divulgação do Programa de Desenvolvimento Urbano de Blumenau. Ano I n.1,jun. 2008. 
BADALOTTI, Rosana Maria et al. Reprodução social da agricultura familiar e juventude rural no oeste catarinense.In: VII RAM - UFRGS, Porto Alegre, Brasil, 2007. Disponível em: http://www.emdialogo.uff.br/sites/default/files/Rosana_Badalotti_et_alli.pdf. Acesso: 20 de fev.2015.

BONAMIGO, Irme Salete; RENK, Arlene; DORIGON, Clóvis.Bem-estar animal e bem-estar dos agricultores frente aos mercados agroalimentares mundializados. In: VII Encontro

Nacional de Estudos do Consumo; III Encontro Luso-Brasileiro de Estudos do Consumo; I Encontro Latino-Americano de Estudos do Consumo.Rio de Janeiro: 24, 25 e 26 de set. de 2014.

COLLIS, Jill; HUSSEY, Roger. Pesquisa em administração: um guia prático para alunos de graduação e pós-graduação. 2. ed. Porto Alegre: Bookman, 2005.

CONAB. A importância da agricultura familiar do desenvolvimento dos municípios. Revista Agropecuária. Disponível em: http://www.revistaagropecuaria.com.br/2012/10/26/aimportancia-da-agricultura-familiar-no-desenvolvimento-dos-municipios/. Acesso em: 14 jan. 2015.

COSTABEBER, José Antonio;CAPORAL, Francisco Roberto. Possibilidades e alternativas para o desenvolvimento rural sustentável. In: VELA, Hugo (org.): Agricultura Familiar e Desenvolvimento Rural Sustentável no Mercosul. Santa Maria: Editora da UFSM/Pallotti, 2003.

CRESWELL, John W. Projeto de Pesquisa: métodos qualitativos, quantitativos e misto. 3.ed. Porto Alegre: Artmed, 2010.

DORIGON, Clóvis. Mercados de produtos coloniais da região Oeste de Santa Catarina: em construção. 2008. Tese (Doutorado em Engenharia de Produção)- Universidade Federal do Rio deJaneiro, Rio de Janeiro, 2008.

FECAM. Rede Municipalista. Disponível em:

http://www.fecam.org.br/conteudo/index.php?cod_menu=13. Acesso em: 13 jun.2014.

FIRJAN. Índice FIRJAN de Desenvolvimento Municipal (IFDM). Disponível em: http://www.firjan.org.br/ifdm/. Acesso em: 28 maio 2014.

GODOY, ArildaSchimidt. Pesquisa qualitativa: tipos fundamentais. Revista de Administração de Empresas. São Paulo, v. 35, n. 3, p. 20-29, Mai./Jun. 1995.

GOMES, Ivair. Sustentabilidade social e ambiental na agricultura familiar. Revista de Biologia e Ciências da Terra v. 5 n. 1, $1^{\circ}$ semestre 2004.

GUILHOTO, Joaquim J.M. et. al. A importância da agricultura familiar no Brasil e em seus estados.In:V Encontro Nacional da Associação Brasileira de Estudos Regionais e Urbanos. Recife, 2007. Disponível em: http://www.anpec.org.br/encontro2007/artigos/A07A089.pdf. Acesso em: 22 fev. 2015. 
GUIMARÃES, Liliana Andolpho;MARTINS, Daniela de Almeida; GUIMARÃES, Patrícia Magalhães. Os métodos qualitativo e quantitativo: similaridades e complementaridade. In: GRUBITS, S.;

NORIEGA, J. A. V. (org.). Método Qualitativo: epistemologia, complementariedades e campos de aplicação. São Paulo: Vetor, 2004.

IBGE.Produção Agrícola Municipal 2012. Disponível em: http://www.ibge.gov.br/home/estatistica/pesquisas/pesquisa_resultados.php?id_pesquisa=44. Acesso em: 02 jun. 2014.

KONRAD, Joice; SILVA, Clécio Azevedoda.Agricultura familiar no oeste catarinense: da colônia àintegração. In: XXI encontro nacional de geografia agrária "territórios em disputa: os desafios da geografia agrária nas contradições do desenvolvimento brasileiro". Uberlândia- MG, 15 a 19 de outubro de 2012.

LOCH, Carlos; WALKOWSKI, Marinês. da Conceição. O processo participativo no planejamento turístico do espaço rural de Alfredo Wagner/SC. Revista Brasileira de Pesquisa em Turismo v. 3, n. 1, p. 46-67, abril 2009. Disponível em http://revhosp.org/ojs/index.php/rbtur/article/view/132/165. Acesso em: 20 jan. 2015.

LUSTOSA, Frederico. Instituições, cultura e desenvolvimento sustentável na bacia cultural do Araripe. Cad. EBAPE.BR, Rio de Janeiro , v. 8, n. 1, Mar. 2010 . Disponível em: $<$ http://www.scielo.br/scielo.php?script=sci_arttext\&pid=S167939512010000100010\&lng=en\&nrm=iso>. Acesso em:22fev. 2015.

MARTINS, Fabíola Mendes. A gestão eficiente e sustentável da propriedade rural familiar em Laguna (SC). Disponível em: http://www.uniedu.sed.sc.gov.br/wpcontent/uploads/2014/01/Fabiola-Mendes-Martins.pdf. Acesso em: 22 fev. 2015.

MEURER, Fabiana; VIEIRA, Guilherme Feijó. Plano diretor para municípios de pequeno porte: a experiência do plano diretor regional participativo da AMAVI. In: Seminário Política e Planejamento, 2, 2010. Curitiba.

MIOR, Luiz Carlos. Agricultores familiares, agroindústrias e redes de desenvolvimento rural.Chapecó: Argos, 2005.

MIOR, Luiz Carlos. Agricultura familiar, agroindústria e desenvolvimento territorial. In: I Colóquio Internacional de Desenvolvimento Territorial Sustentável. Florianópolis, 22 a 25 de agosto de 2007.

PREFEITURA MUNICIPAL DE GUATAMBU SC. Apresentação. Disponível em: http://www.guatambu.sc.gov.br/home/index.php?\#. Acesso em: 09 maio 2014.

PTDRS. Oeste Catarinense. Ministério do Desenvolvimento Agrário(MDA), 2010.

ROVER, Oscar José; LANZARIN, Alison. O cooperativismo de leite do oeste de Santa Catarina/ Brasil e a inclusão sócio-econômica de agricultores familiares em condições vulneráveis.In: V Encontro de Pesquisadores Latino-Americanos do Cooperativismo. 
Ribeirão Preto-SP,2008. Disponível em:

http://www.fundace.org.br/cooperativismo/arquivos_pesquisa_ica_la_2008/058-rover.pdf. Acesso em: 24 fev. 2015.

SEN, Amartya. Desenvolvimento como liberdade. São Paulo: Companhia das Letras, 2010.

VERGARA, Sylvia Constant. Projetos e relatórios de pesquisa em Administração. 14 ed. São Paulo: Atlas, 2013.

WINCK, Cesar Augustus. Impactos do pagamento pela qualidade na cadeia produtiva do leite na região Oeste de Santa Catarina. 2012. Tese (Doutorado em Agronegócio) Universidade Federal do Rio Grande do Sul, Porto Alegre, 2012.

YIN, Robert K. Estudo de Caso: planejamento e métodos. 4 ed. Porto Alegre: Bookman, 2010. 